\title{
Multiparametric cystoscopy: opportunities to enhance bladder cancer detection
}

\author{
Jacob Taylor ${ }^{1}$, Richard S. Matulewicz ${ }^{1,2}$ \\ ${ }^{1}$ Department of Urology, ${ }^{2}$ Department of Population Health, NYU Grossman School of Medicine, New York, NY, USA \\ Correspondence to: Richard S. Matulewicz, MD, MS. 227 E 30 ${ }^{\text {th }}$ St., Room 629G, New York, NY 10017, USA. \\ Email: Richard.Matulewicz@nyulangone.org. \\ Comment on: Kriegmair MC, Rother J, Grychtol B, et al. Multiparametric Cystoscopy for Detection of Bladder Cancer Using Real-time Multispectral \\ Imaging. Eur Urol 2020;77:251-9.
}

Submitted Apr 04, 2020. Accepted for publication May 11, 2020.

doi: $10.21037 /$ tau-20-848

View this article at: http://dx.doi.org/10.21037/tau-20-848

The majority ( $75 \%)$ of incident bladder cancer cases are non-muscle invasive (NMIBC) (1). These tumors have high rates of recurrence and progression that significantly contribute to the cost and morbidity associated with each bladder cancer diagnosis. Cystoscopy with transurethral resection of bladder tumors (TURBT) is a diagnostic and therapeutic procedure. Accordingly, optimal identification of all visible tumors during each cystoscopy is essential for accurate staging and therefore treatment. The current gold standard modality is white light cystoscopy (WLC). However, novel cystoscopic imaging modalities such as photodynamic diagnostic (PDD, aka fluorescence) cystoscopy are being increasingly adopted and recommended for use by societal guidelines (2). These recommendations are supported by a growing body of literature that suggests lower recurrence and long-term progression rates when compared to traditional WLC (3). WLC sufficiently identifies large papillary lesions, but has well known limitations such as missing multi-focal lesions, microscopic or flat lesions such as carcinoma in-situ (CIS), or misidentifying dysplasia or inflammation (4). Given the importance of accurate staging and oncologic risks of missed lesions, there is a need to develop and implement new techniques and modalities that can improve the detection of bladder tumors.

In their article entitled "Multiparametric Cystoscopy for Detection of Bladder Cancer Using Real-time Multispectral Imaging", published in European Urology, Kriegmair and colleagues reported results from a feasibility study using novel multiparametric cystoscopy technology with real-time image fusion (5). In their study of 10 patients, real-time multispectral imaging enhanced cystoscopy was created using a camera, light source, microcontroller, and a filtered video-adapter. White light, enhanced vascular contrast (EVC), blue light fluorescence (PDD), protoporphyrin IX fluorescence, and autofluorescence (AF) were used independently and then merged into one image to scan the bladder and identify lesions, after which point standard cystoscopy was used to resect all lesions. Two independent urologists performed post-surgical analysis of the images on all modalities to grade lesions on a 4-point Likert scale from "not suspicious" to "clearly suspicious".

Using multi-spectral imaging, the authors found 31 lesions in 10 patients, 27 of which were malignant in 9 patients. The majority of lesions were low-grade (LG) Ta $(n=22)$ with $2 / 5$ high-grade lesions CIS. Multiparametric imaging had the highest probability of being score "clearly suspicious", followed by PDD at 0.57 and white light at 0.47 . All five modalities had a probability greater than zero of completely missing a lesion, while the fused multiparametric imaging did not $(\mathrm{P}=0.128)$. They also suggest the possibility of this technique improving the detection of flat lesions. However, PDD correlated closely to overall multiparametric imaging scores among flat lesions, suggesting that PDD may be driving the increase in the multiparametric score with marginal value added by other modalities. Furthermore, there were only 2 (7.4\%) CIS lesions, making the true improvement of CIS detection difficult to assess. High-grade NMIBC detection, particularly CIS lesion detection, is a common endpoint of 
other studies that suggests a $12 \%$ and $27 \%$ increase in CIS detection with PDD (6) or narrow-band imaging (NBI) (7), respectively.

The authors should be congratulated on their early results showing technical feasibility of fusing multiple imaging modalities during real-time cystoscopy. This technique shows promise to overcome limitations of PDD and NBI with complementary strengths of other imaging modalities such as EVC. As this technique further evolves and is validated, combining multiparametric cystoscopy with microscopic biopsy techniques such as confocal laser endomicroscopy and optical coherence tomography has the potential to improve biopsy accuracy and staging (8). Optical coherence tomography, a high-resolution subsurface imaging technique, provides a high positive predictive value and when combined with PDD decreased false negative biopsies increasing specificity from $62 \%$ to $87 \%$ in a single centered study (9). Overlaying other developing deep learning technologies has the potential to further improve diagnostic yields (10).

As larger prospective data is collected, it will also be important for future research to assess the learning curve of multiparametric cystoscopy while also studying its dissemination and implementation in the community. Although most urologists are facile with WLC, the learning curve for photodynamic cystoscopy using hexaminolevulinate hydrochloride was 20 cases for training urologists with sustained decrease in the false positive rate seen at up to 50 cases (11). The relatively slow diffusion and uptake of new technology may delay the impact multiparametric cystoscopy has in the short term, but these aggregate technologic gains will continue to drive improvements in bladder cancer outcomes.

\section{Acknowledgments}

Funding: None.

\section{Footnote}

Provenance and Peer Review: This article was commissioned by the editorial office, Translational Andrology and Urology. The article did not undergo external peer review.

Conflicts of Interest: Both authors have completed the ICMJE uniform disclosure form (available at http://dx.doi. org/10.21037/tau-20-848). The authors have no conflicts of interest to declare.
Ethical Statement: The authors are accountable for all aspects of the work in ensuring that questions related to the accuracy or integrity of any part of the work are appropriately investigated and resolved.

Open Access Statement: This is an Open Access article distributed in accordance with the Creative Commons Attribution-NonCommercial-NoDerivs 4.0 International License (CC BY-NC-ND 4.0), which permits the noncommercial replication and distribution of the article with the strict proviso that no changes or edits are made and the original work is properly cited (including links to both the formal publication through the relevant DOI and the license). See: https://creativecommons.org/licenses/by-nc-nd/4.0/.

\section{References}

1. Burger M, Catto JW, Dalbagni G, et al. Epidemiology and risk factors of urothelial bladder cancer. Eur Urol 2013;63:234-41.

2. Taylor J, Becher E, Steinberg GD. Update on the guideline of guidelines: non-muscle-invasive bladder cancer. BJU Int 2020;125:197-205.

3. Chou R, Selph S, Buckley DI, et al. Comparative Effectiveness of Fluorescent Versus White Light Cystoscopy for Initial Diagnosis or Surveillance of Bladder Cancer on Clinical Outcomes: Systematic Review and Meta-Analysis. J Urol 2017;197:548-58.

4. Lee CS, Yoon CY, Witjes JA. The past, present and future of cystoscopy: the fusion of cystoscopy and novel imaging technology. BJU Int 2008;102:1228-33.

5. Kriegmair MC, Rother J, Grychtol B, et al. Multiparametric Cystoscopy for Detection of Bladder Cancer Using Real-time Multispectral Imaging. Eur Urol 2020;77:251-9.

6. Lerner SP, Liu H, Wu MF, et al. Fluorescence and white light cystoscopy for detection of carcinoma in situ of the urinary bladder. Urol Oncol 2012;30:285-9.

7. Geavlete B, Multescu R, Georgescu D, et al. Narrow band imaging cystoscopy and bipolar plasma vaporization for large nonmuscle-invasive bladder tumors--results of a prospective, randomized comparison to the standard approach. Urology 2012;79:846-51.

8. Zlatev DV, Altobelli E, Liao JC. Advances in imaging technologies in the evaluation of high-grade bladder cancer. Urol Clin North Am 2015;42:147-57, vii.

9. Schmidbauer J, Remzi M, Klatte T, et al. Fluorescence cystoscopy with high-resolution optical coherence 
tomography imaging as an adjunct reduces false-positive findings in the diagnosis of urothelial carcinoma of the bladder. Eur Urol 2009;56:914-9.

10. Shkolyar E, Jia X, Chang TC, et al. Augmented Bladder Tumor Detection Using Deep Learning. Eur Urol

Cite this article as: Taylor J, Matulewicz RS. Multiparametric cystoscopy: opportunities to enhance bladder cancer detection. Transl Androl Urol 2020;9(5):2302-2304. doi:10.21037/tau-20-848
2019;76:714-8.

11. Gravas S, Efstathiou K, Zachos I, et al. Is there a learning curve for photodynamic diagnosis of bladder cancer with hexaminolevulinate hydrochloride? Can J Urol 2012;19:6269-73. 